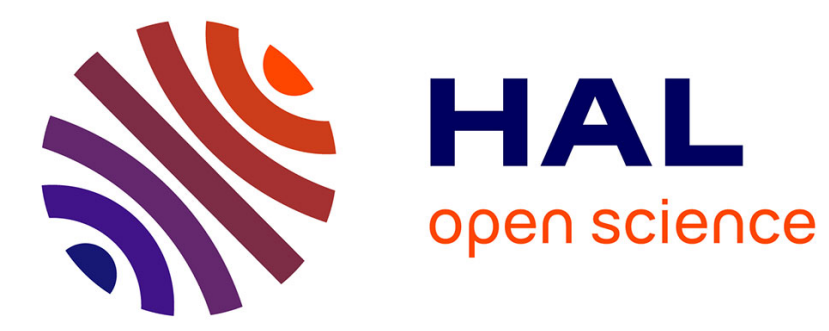

\title{
Structural analysis of chemical and topological inhomogeneities by ASAXS \\ H.-G. Haubold
}

\section{To cite this version:}

H.-G. Haubold. Structural analysis of chemical and topological inhomogeneities by ASAXS. Journal de Physique IV Proceedings, 1993, 03 (C8), pp.C8-475-C8-479. 10.1051/jp4:1993899 . jpa-00252330

\section{HAL Id: jpa-00252330 https://hal.science/jpa-00252330}

Submitted on 1 Jan 1993

HAL is a multi-disciplinary open access archive for the deposit and dissemination of scientific research documents, whether they are published or not. The documents may come from teaching and research institutions in France or abroad, or from public or private research centers.
L'archive ouverte pluridisciplinaire HAL, est destinée au dépôt et à la diffusion de documents scientifiques de niveau recherche, publiés ou non, émanant des établissements d'enseignement et de recherche français ou étrangers, des laboratoires publics ou privés. 


\title{
Structural analysis of chemical and topological inhomogeneities by ASAXS
}

\author{
H.-G. HAUBOLD \\ Institut für Festkörperforschung, Forschungszentrum Jülich, Postfach 1913, 5170 Jülich, Germany
}

\begin{abstract}
From ASAXS measurements partial pair correlations can be determined both in the fluctuations $\Delta \mathrm{c}_{\mathrm{i}}(\underline{\mathrm{r}})=\mathrm{c}_{\mathrm{i}}(\underline{\mathrm{r}})-\overline{\mathrm{c}}_{\mathrm{i}}$ of the local concentrations $\mathrm{c}_{\mathrm{i}}(\underline{\mathrm{r}})=\mathrm{n}_{\mathrm{i}}(\underline{\mathrm{r}}) / \mathrm{n}(\underline{\mathrm{r}})$ of the $\mathrm{i}^{\text {th }}$ species and in the fiuctuations $\Delta n(\underline{r})=n(\underline{r})-\bar{n}$ of the local number density of all kinds of atoms. This requires a separation of the measured intensity into partial intensities which depend linearly on the squared average atomic form factor, form factor differences and cross terms. The structural analysis is illustrated for the example of simple 2-phase models.
\end{abstract}

\section{Introduction}

In general the interpretation of SAS scattering from multicompositional samples is not unambiguous: Inhomogeneities of both compositional (=chemical) and topological (=density) origin may contribute to the scattered intensity and an identification of the individual scattering contributions is not possible. Especially in studies of early stages of precipitation in metallic alloys or semiconductors high background scattering contributions from pure density defects as voids, grain boundaries or rough sample surfaces arise and cannot be subtracted without additional assumptions.

Given even the case of a background-free SAS study of the most simple compositional inhomogeneities as illustrated in Fig. 1, the full structural characterization requires the knowledge of their scattering contrast $\Delta \rho_{\mathbf{f}}$. This, however, cannot be retrieved from the scattering cross section as measured at $1 \mathrm{X}$-ray energy

$$
\frac{\mathrm{d} \sigma}{\mathrm{d} \Omega}(\underline{\mathrm{Q}})=\mathrm{N} \cdot \Delta \rho_{\mathrm{f}}^{2} \cdot \mathrm{F}(\underline{\mathrm{Q}})^{2} \cdot \varphi(\underline{\mathrm{Q}})
$$

independently on other unknowns as $\mathrm{N}=$ particle number, $F=$ particle formfactor and $\varphi=$ interparticle interference.

\section{Anomalous scattering for contrast variation}

The analysis of the scattering contrast requires anomalous small angle X-ray scattering (=ASAXS) measurements $\frac{\mathrm{d} \sigma}{\mathrm{d} \Omega}(\underline{Q}, \mathrm{E})$ at more than $1 \mathrm{X}$-ray energy E. In an ASAXS experiment the intense continuous energy spectrum of synchrotron radiation is used to tune the incident photon energy 

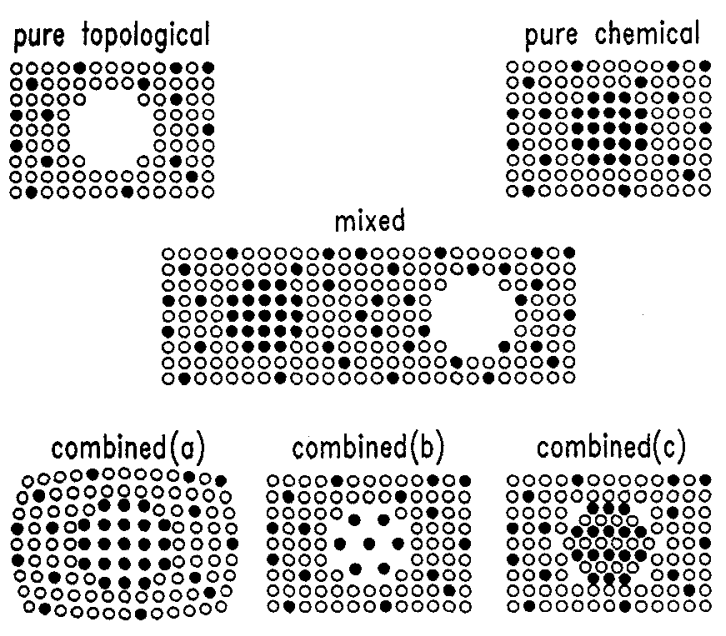

Fig.1: Topological and chemical inhomogeneities with identical particle formfactors in samples with 2 kinds of atoms $1(\bullet)$ and $2(\bullet)$. Differences in their SAS arise merely from their different scattering contrast $\Delta \rho_{\mathrm{f}}=\overline{\mathrm{f}}$ (pure topological $), \Delta \rho_{\mathrm{f}}=\mathrm{f}_{1}-\overrightarrow{\mathrm{f}}=\overline{\mathrm{c}}_{2}\left(\mathrm{f}_{1}-\mathrm{f}_{2}\right)$ (pure chemical), $\Delta \rho_{\mathrm{f}}=\mathrm{n}_{1} / \mathrm{n}_{\mathrm{M}} \mathrm{f}_{1}-\overline{\mathrm{f}}-$ $\frac{\Delta \mathrm{V}}{\mathrm{V}} \cdot \mathrm{K}(\underline{\mathrm{Q}} / \mathrm{Q}) \overline{\mathrm{f}}$ (combined, a), $\Delta \rho_{\mathrm{f}}=$ $\mathrm{n}_{1} / \mathrm{n}_{\mathrm{M}} \mathrm{f}_{1}-\overline{\mathrm{f}}$ (combined, b) and $\Delta \rho_{\mathrm{f}}$ $\mathrm{n}_{1} / \mathrm{n}_{\mathrm{M}} \mathrm{f}_{1}+\mathrm{n}_{2} / \mathrm{n}_{\mathrm{M}} \mathrm{f}_{2}-\overline{\mathrm{f}}$ (combined, c). $\mathrm{n}_{\mathrm{m}}, \mathrm{n}_{\mathrm{i}}$ are the local number densities of atoms in the matrix $M$ and of the individual kinds $i$, respectively. The $f_{i}$ 's are the atomic formfactors and $\bar{f}=$ $\sum_{\mathrm{i}} \overline{\mathrm{c}}_{\mathrm{i}} \mathrm{f}_{\mathrm{i}}$ is the mean atomic formfactor. $\Delta \mathrm{V} / \mathrm{V} \cdot \mathrm{K} \cdot \overline{\mathrm{f}}$ is the scattering contribution of displaced matrix atoms; $\Delta \mathrm{V} / \mathrm{V}$ is a relaxation volume and $K$ amounts to the order of $1 / 4 /$.

close to the absorption edges of the individual elements. This varies their atomic scattering amplitudes (=atomic formfactors)

$$
f_{i}(E)=f_{0, i}+f_{i}^{\prime}(E)+i f_{i}^{\prime \prime}(E)
$$

up to about $20 \%$ by anomalous scattering.

$f$ 'values at the low energy side of the absorption edge can be taken from $f^{\prime}$-values for free atoms by Cromer and Liberman /1/, when possible chemical shifts of the absorption edge energies are taken into account by the normalization of the energy scale to the measured edge energy. The $f^{\prime}$-values in all other regimes, especially very close and within the edge region have to be calculated from the f"-values using the Kramers-Kronig /2/ relation. $\mathrm{f}$ " for each element is directly obtained from the photoelectric absorption cross section for this element via the optical theorem $/ 3 /$.

For a contrast analysis, we measure $\mathrm{d} \sigma / \mathrm{d} \Omega(\underline{\mathrm{Q}}, \mathrm{E})$ for more than $1 \mathrm{X}$-ray energy and apply the known energy dependencies of the atomic formfactors $f_{i}(E)$ to probe the scattering contrast in question: Scattering from pure topological (=density) inhomogeneities like e.g. voids, dislocations, grain boundaries or roughness of the sample surface is identified for the finding $\mathrm{d} \sigma / \mathrm{d} \Omega(\mathrm{E}) \sim|\overrightarrow{\mathrm{f}}(\mathrm{E})|^{2}$ for all $\underline{\mathrm{Q}}$ 's. $\overrightarrow{\mathrm{f}}=\sum_{\mathrm{i}} \overline{\mathrm{c}}_{\mathrm{i}} \mathrm{f}_{\mathrm{i}}$ is the mean atomic formfactor. Given the case of pure chemical inhomogeneities, e.g. a binary system containing compositional different precipitates with an unchanged local number density of atoms within the precipitate, $\mathrm{d} \sigma / \mathrm{d} \Omega(\mathrm{E}) \sim$ $\left|f_{1}(E)-f_{2}(E)\right|^{2}=|\Delta f(E)|$ will be identified for all $\underline{Q}$-vectors. For all combined inhomogeneities the situation becomes more complex: $|\overline{\mathrm{f}}|^{2},|\Delta \mathrm{f}|^{2}$ and $\overline{\mathrm{f}} \Delta \mathrm{f}$ contributions will arise.

As a first step of data interpretation it is desirable to probe for all three of these scattering contributions. This becomes possible because of their quite different energy dependence, which is illustrated in Fig. 2 for a $\mathrm{Fe}_{0.75} \mathrm{Gd}_{0.25}$-alloy. Applied to the situation of a sample containing a mixture of pure topological and pure chemical inhomogeneities

$$
\frac{\mathrm{d} \sigma}{\mathrm{d} \Omega}=\mathrm{N}_{\mathrm{P}}\left|\mathrm{f}_{1}-\overline{\mathrm{f}}\right|^{2} \mathrm{~F}_{\mathrm{P}}^{2} \varphi_{\mathrm{P}}+\mathrm{N}_{\mathrm{V}}|\overline{\mathrm{f}}|^{2} \mathrm{~F}_{\mathrm{V}}^{2} \varphi_{\mathrm{V}}
$$




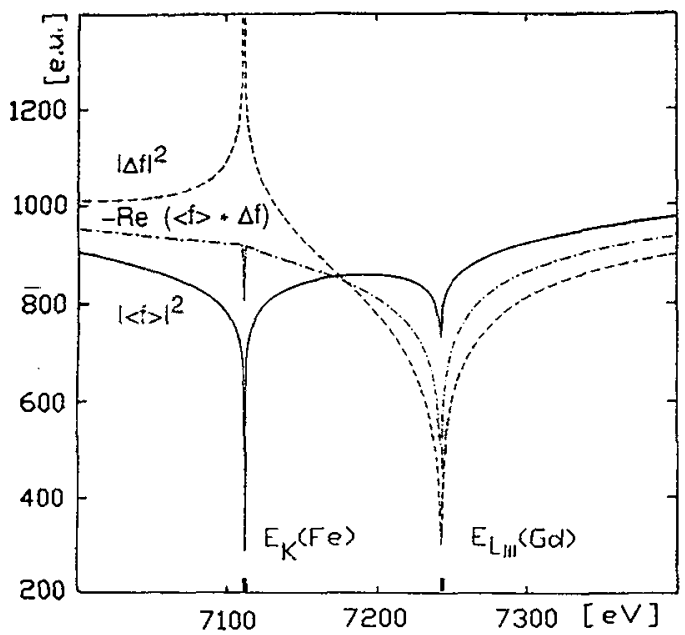

Fig.2: Contrast terms $|\Delta \mathrm{f}|^{2}=\mid \mathrm{f}_{\mathrm{Gd}}-$ $\left.\mathrm{f}_{\mathrm{Fe}}\right|^{2},|\overline{\mathrm{f}}|^{2}=\left|\overline{\mathrm{c}} \mathrm{f}_{\mathrm{Gd}}+(1-\overline{\mathrm{c}}) \mathrm{f}_{\mathrm{Fe}}\right|^{2}$ and $-\mathrm{Re}$ $\left\{\overline{\mathrm{f}}^{*} \cdot \Delta \mathrm{f}\right\}$ near the $\mathrm{K}(\mathrm{Fe})$ and $\mathrm{L}_{\mathrm{III}}(\mathrm{Gd})$ absorption edges of a $\mathrm{Fe}_{0.75} \mathrm{Gd}_{0.25}$ alloy. The f'- and f"-values were taken from a Cromer-Liberman calculation for free atoms.

a measurement at 2 energies enables to separate the individual scattering contributions

$$
\frac{1}{\left|\overline{\mathrm{f}}\left(\mathrm{E}_{1}\right)\right|^{2}} \frac{\mathrm{d} \sigma}{\mathrm{d} \Omega}\left(\mathrm{E}_{1}\right)-\frac{1}{\left|\overline{\mathrm{f}}\left(\mathrm{E}_{2}\right)\right|^{2}} \frac{\mathrm{d} \sigma}{\mathrm{d} \Omega}\left(\mathrm{E}_{2}\right)=\left\{\left|\frac{\mathrm{f}_{1}}{\overline{\mathrm{f}}}\left(\mathrm{E}_{1}\right)-1\right|^{2}-\left|\frac{\mathrm{f}_{1}}{\overline{\mathrm{f}}}\left(\mathrm{E}_{2}\right)-1\right|^{2}\right\} \mathrm{F}_{\mathrm{P}}^{2} \varphi_{\mathrm{P}}
$$

Given combined inhomogeneities

$$
\frac{\mathrm{d} \sigma}{\mathrm{d} \Omega}=\mathrm{N}_{\mathrm{P}}\left|\frac{\mathrm{n}_{1}}{\mathrm{n}_{\mathrm{M}}} \mathrm{f}_{1}-\left(1+\frac{\Delta \mathrm{V}}{\mathrm{V}} \cdot \mathrm{K}\right) \overline{\mathrm{f}}\right|^{2} \mathrm{~F}_{\mathrm{P}}^{2} \varphi_{\mathrm{P}}
$$

the otherwise unknown quantity $n_{1}=n_{M}\left(1+\frac{\Delta V}{V} K\left(\frac{Q}{Q}\right)\right)$ may be retrieved from a plot $\sqrt{\frac{1}{|\bar{\Gamma}|^{2}} \frac{d \sigma}{d \Omega}(E)}$ versus $\frac{\mathfrak{f}_{1}}{\vec{f}}(E)$. Measurements with anisotropic single crystals along crystallographic directions with different $K$ values /4/ yield both $n_{1} / n_{M}$ and $\frac{\Delta V}{V}$ separately.

\section{Beyond the 2-phase models}

Generally the SAS cross section writes

$$
\begin{aligned}
\frac{d \sigma}{d \Omega}(\underline{Q}, E) & =\frac{1}{V_{s}}\left|\int_{V_{s}} \sum_{i} \Delta n_{i}(\underline{r}) f_{i}(E) \exp (i \underline{Q} \underline{r}) d^{3} r\right|^{2} \\
& =\sum_{i, j} f_{i}^{*}(E) f_{i}(E) S_{i, j}(\underline{Q}) \\
\mathrm{S}_{\mathrm{i}, \mathrm{j}}(\underline{\mathrm{Q}}) & \left.=\frac{1}{V_{s}} \int_{V_{s}}<\Delta n_{i}(\underline{r}) \Delta n_{j}\left(\underline{r}-\underline{r}^{\prime}\right)\right\rangle_{\underline{r}^{\prime}} \exp (\underline{i \underline{Q}}) d^{3} r
\end{aligned}
$$

$\Delta n_{i}(\underline{r})=n_{j}(\underline{r})-\bar{n}_{i}$ are the fluctuations in the local number densities $n_{i}(\underline{r})$ of the individual atoms i. The scattering cross section may be expressed as a weighted sum of partial structure factors $S_{i, j}(\underline{Q})$, which are the Fourier transforms of the partial pair correlations $\left\langle\Delta n_{i}(\underline{r}) \Delta n_{j}\left(\underline{r}-\underline{r}^{\prime}\right)>_{\underline{r}^{\prime}}\right.$ in the fluctuations $\Delta \mathrm{n}_{\mathrm{i}}(\mathrm{r})$. They can be retrieved from the set of linear Eq. (7), which is obtained from ASAXS measurements at different X-ray energies with varied atomic formfactors.

However, to answer the question for a topological or chemical origin of the $\Delta n_{i}$-fluctuations, it becomes favourable to decompose

$$
\Delta n_{i}(\underline{r})=n(\underline{r}) \Delta c_{i}(\underline{r})-\bar{c}_{i} \Delta n(\underline{r})
$$


For each atomic species $\mathrm{i}$, fluctuations $\Delta \mathrm{n}_{\mathbf{i}}(\underline{\underline{r}})$ can arise from compositional fluctuations $\Delta c_{i}(\underline{r})=$ $c_{i}(\underline{r})-\bar{c}_{i}$ in their local concentration $c_{i}(\underline{r})=n_{i}(\underline{r}) / n(\underline{r})$ and from pure density fluctuations $\Delta \mathrm{n}(\underline{\mathbf{r}})=$ $n(\underline{r})-\bar{n}$ in the local total number density $n(\underline{r})=\sum_{i} n_{i}(\underline{r})$ of all kinds of atoms.

For binary systems Eqs. 6 and 9 then yield the following Bhatia-Thornton expression

$$
\begin{aligned}
\frac{\mathrm{d} \sigma}{\mathrm{d} \Omega}(\underline{\mathrm{Q}}, \mathrm{E}) & =|\bar{f}(E)|^{2} S_{N N}(\underline{Q})+|\Delta f(E)|^{2} S_{C C}(\underline{Q})+2 R e\left\{\bar{f}^{*} \Delta f\right\} S_{N C}(\underline{Q}) \\
\mathrm{S}_{\mathrm{NN}}(\underline{\mathrm{Q}}) & =\frac{1}{V_{s}} \int_{V_{s}}\left\langle\Delta n(\underline{r}) \Delta n\left(\underline{r}-\underline{r}^{\prime}\right)\right\rangle_{\underline{r}^{\prime}} \exp (i \underline{Q} \underline{r}) d^{3} r \\
\mathrm{~S}_{\mathrm{CC}}(\underline{\mathrm{Q}}) & =\bar{n}^{2} \frac{1}{V_{s}} \int_{V_{s}}\left\langle\tilde{\Delta} c(\underline{r}) \tilde{\Delta} c\left(\underline{r}-\underline{r}^{\prime}\right)\right\rangle_{\underline{\underline{r}}^{\prime}} \exp (i \underline{\underline{Q}} \underline{r}) d^{3} r \\
\mathrm{~S}_{\mathrm{NC}}(\underline{\mathrm{Q}}) & =\bar{n} \frac{1}{V_{s}} \int_{V_{s}}\left\langle\Delta n(\underline{r}) \tilde{\Delta c}\left(\underline{r}-\underline{r}^{\prime}\right)\right\rangle_{\underline{\underline{x}}^{\prime}} \exp (i \underline{Q} \underline{\underline{r}}) d^{3} r \\
\tilde{\Delta} \mathrm{c}(\underline{\mathrm{r}}) & \left.=\frac{n(\underline{r})}{\bar{n}}\left(c_{\mathbf{l}}(\underline{r})-\bar{c}_{1}\right)\right)
\end{aligned}
$$

The small angle scattering cross section then is expressed as a weighted sum of partial structure factors $S_{N N}$ for pure topological (=density) fluctuations, $S_{C C}$ for pure chemical (=compositional) fluctuations and a factor $\mathrm{S}_{\mathrm{NC}}$, which contains the correlations. From a set of at least 3 ASAXS measurements with the varied prefactors $|\overline{\mathrm{f}}(\mathrm{E})|^{2},|\Delta \mathrm{f}(\mathrm{E})|^{2}$ and $\operatorname{Re}\left\{\overline{\mathrm{f}}^{*} \Delta \mathrm{f}\right\}$, all 3 partials can be determined. For ternary systems, e.g. the scattering contrast is

$$
\sum_{i} \Delta c_{i}(\underline{r}) f_{i}=\Delta c_{1}(\underline{r})\left(f_{1}-f_{3}\right)+\Delta c_{2}(\underline{r})\left(f_{2}-f_{3}\right)
$$

where additional fluctuations and additional form factor differences are included.

Given the case of multicomponent materials, possible findings are

$\mathrm{S}_{\mathrm{CC}}=0$, necessarily in connection with $\mathrm{S}_{\mathrm{NC}}=0$, and $\mathrm{S}_{\mathrm{NN}} \neq 0$ :

This is a material where scattering arises only from density fluctuations, e.g. in the form of voids, grain boundaries, dislocations or surface inhomogeneities.

$\mathrm{S}_{\mathrm{CC}} \neq 0, \quad \mathrm{~S}_{\mathrm{NC}}=0 \quad$ and $\quad \mathrm{S}_{\mathrm{NN}}=0$ :

This is the observation for pure compositional inhomogeneities with no changes in the number density of atoms. Density defects are not detected.

$\mathrm{S}_{\mathrm{CC}} \neq 0, \quad \mathrm{~S}_{\mathrm{NC}}=0 \quad$ and $\quad \mathrm{S}_{\mathrm{NN}} \neq 0$ :

In this case, additional topological inhomogeneities are formed in the sample. No correlation exists between compositional and density fluctuations.

$\mathrm{S}_{\mathrm{CC}} \neq \mathrm{Q}, \mathrm{S}_{\mathrm{NC}} \neq 0 \quad$ and $\quad \mathrm{S}_{\mathrm{NN}} \neq 0$ :

This is a more complex, but most general case. Both compositional and topological inhomogeneities are present and correlations exit. Whereas the $S_{C C}$ and $S_{N C}$ contributions are directly connected to concentration fluctuations, the $S_{N N}$ contribution may arise also from noncorrelated additional topological inhomogeneities. Scattering from precipitates of a different chemical phase with different total number density of atoms will give a contribution $\mathrm{S}_{\mathrm{NN}}^{\mathrm{P}}$. Additional, uncorrelated pure density defects such as voids, e.g. contribute along with $\mathrm{S}_{\mathrm{NN}}^{\mathrm{V}}$ to $\mathrm{S}_{\mathrm{NN}}=\mathrm{S}_{\mathrm{NN}}^{\mathrm{P}}+\mathrm{S}_{\mathrm{NN}}^{\mathrm{V}}$. Without Fourier backtransforms of $S_{C C}$ and $S_{N C}$, the separation of $S_{N N}$ becomes possible, when both the $S_{\mathrm{CC}^{-}}$and $\mathrm{S}_{\mathrm{NC}}$-terms show the same $(\underline{Q})$ dependence, or in other words, when the ratio $\mathrm{S}_{\mathrm{NC}}(\underline{\mathrm{Q}}) / \mathrm{S}_{\mathrm{CC}}(\underline{\mathrm{Q}})$ becomes independent of $\underline{\mathrm{Q}}$. Accordingly, equal $\underline{\mathrm{r}}$ dependences $\Delta \mathrm{n}(\underline{\mathrm{r}}) \sim \tilde{\Delta} c(\underline{\mathrm{r}})$ lead to the relation

$$
\frac{\mathrm{S}_{\mathrm{NC}}^{2}(\underline{Q})}{\mathrm{S}_{\mathrm{NN}}^{\mathrm{P}}(\underline{Q}) \mathrm{S}_{\mathrm{CC}}(\underline{Q})}=1
$$


whereas the general case is

$$
0 \leq \frac{\mathrm{S}_{\mathrm{NC}}^{2}(\underline{\mathrm{Q}})}{\mathrm{S}_{\mathrm{NN}}(\underline{\mathrm{Q}}) \mathrm{S}_{\mathrm{CC}}(\underline{\mathrm{Q}})} \leq 1
$$

From Eq. (16) $\mathrm{S}_{\mathrm{NN}}^{\mathrm{P}}(\underline{\mathrm{Q}})$ can then be determined and the complete separation of precipitate scattering from the topological background scattering contribution is achieved directly.

The split individual scattering contributions may then be analyzed in the framework of simple two-phase models, or according to Eq. (7) in terms of density pair correlations, using the relations $\left(\bar{c}_{1}=\mathrm{c}\right)$.

$$
\begin{aligned}
& S_{11}=c^{2} S_{N N}+2 c R e\left\{S_{N C}\right\}+S_{C C} \\
& S_{12}=c(1-c) S_{N N}+(1-2 c) \operatorname{Re}\left\{S_{N C}\right\}-i \operatorname{Im}\left\{S_{N C}\right\}-S_{C C} \\
& S_{22}=(1-c)^{2} S_{N N}-2(1-c) \operatorname{Re}\left\{S_{N C}\right\}+S_{C C}
\end{aligned}
$$

\section{Conclusions}

In ASAXS studies of multicomponent materials it is favorable to separate the measured scattering cross section into partials which depend linearly on the squared average atomic form factor $|\bar{f}|^{2}$, form factor differences $|\Delta f|^{2}$ and cross terms of $2 \operatorname{Re}\left\{\bar{f}^{*} \Delta f\right\}$. This allows a direct separation of the concentration fluctuation dependent scattering from other topological background scattering intensities, which arise from additional topological disorder present in most materials. Applications are studies of precipitation in metallic alloys and semiconductors, as well as larger scale concentration fluctuations in amorphous materials.

\section{References}

/1/ CROMER D.T., LIBERMAN D., J. Chem. Phys. 53 (1970) 1891

/2/ KRAMERS H.A., Phys. Z. 30 (1929) 522 KRONIG R. de L., J. Opt. Soc. Amer. 12 (1926) 547

/3/ JAMES R.W., The Optical Principles of the Diffraction of X-rays, Bell \& Sons Ltd., London, 1958

14/ HAUBOLD H.-G., Rad. Effects 78 (1983) 385 